This item was submitted to Loughborough's Research Repository by the author.

Items in Figshare are protected by copyright, with all rights reserved, unless otherwise indicated.

\title{
Interacting effects of climate change and habitat fragmentation on drought- sensitive butterflies
}

PLEASE CITE THE PUBLISHED VERSION

http://dx.doi.org/10.1038/nclimate2746

\section{PUBLISHER}

(C) 2015 Macmillan Publishers Limited

\section{VERSION}

AM (Accepted Manuscript)

\section{PUBLISHER STATEMENT}

This work is made available according to the conditions of the Creative Commons Attribution-NonCommercialNoDerivatives 4.0 International (CC BY-NC-ND 4.0) licence. Full details of this licence are available at: https://creativecommons.org/licenses/by-nc-nd/4.0/

\section{LICENCE}

CC BY-NC-ND 4.0

\section{REPOSITORY RECORD}

Oliver, Tom H., Harry H. Marshall, Mike D. Morecroft, Tom Brereton, Christel Prudhomme, and Chris Huntingford. 2019. "Interacting Effects of Climate Change and Habitat Fragmentation on Drought-sensitive Butterflies". figshare. https://hdl.handle.net/2134/20932. 


\title{
Interacting effects of climate change and habitat
}

\section{fragmentation on drought-sensitive butterflies}

\author{
Tom H. Oliver ${ }^{1 *}$, Harry H. Marshall ${ }^{2}$, Mike D. Morecroft ${ }^{3}$, Tom Brereton ${ }^{4}$, Christel \\ Prudhomme $^{1}$, Chris Huntingford ${ }^{1}$
}

${ }^{1}$ NERC Centre for Ecology and Hydrology, Wallingford, Oxfordshire, OX10 8BB, U.K.

${ }^{2}$ University of Exeter, Penryn Campus, Penryn, Cornwall, TR10 9FE

${ }^{3}$ Natural England, Foundry House,3 Millsands, Riverside Exchange, Sheffield, S3 8NH

${ }^{4}$ Butterfly Conservation, Manor Yard, East Lulworth, Wareham, Dorset, BH20 5QP, UK.

* Author for correspondence: Tom H. Oliver, E: toliver@ceh.ac.uk; T: + 44 (0)1491

692314; F: +44 (0)1491692424 
Climate change is expected to increase the frequency of some climatic extremes ${ }^{1 ; 2}$. These may have dramatic impacts on biodiversity ${ }^{3 ; 4}$, particularly if meteorological thresholds are crossed, leading to population collapses. Should this occur repeatedly, populations may be unable to recover, resulting in local extinctions. Comprehensive time series data on butterflies in Great Britain provide a rare opportunity to quantify population responses to both past severe drought and the interaction with habitat area and fragmentation. Here, we combine this knowledge with future projections from multiple climate models, for different Representative Concentration Pathways (RCPs), and for simultaneous modelled responses to different landscape characteristics. Under RCP8.5, that is associated with 'business-as-usual' emissions, widespread drought-sensitive butterfly population extinctions could occur as early as 2050. However by managing landscapes and particularly reducing habitat fragmentation, the probability of persistence until mid-century improves from around zero to between 6-42\% (95\% CI). Achieving persistence with a greater than $50 \%$ chance and right through to 2100 is only possible under both low climate change (RCP2.6) and semi-natural habitat restoration. Our data show that, for these drought-sensitive butterflies, persistence is achieved more effectively by restoring semi-natural landscapes to reduce fragmentation, rather than simply focussing on increasing habitat area, but this will only be successful in combination with substantial emission reductions.

There is strong evidence that climate change will have increasingly large impacts on biodiversity $^{3-6}$. This is especially so from increases in the frequency of extreme events, although the impacts of these have been less studied than responses to gradual changes in climatological means ${ }^{4}$. Species responses to climate can be highly nonlinear, with threshold effects of extreme weather events, and in particular droughts, causing population collapses ${ }^{7-9}$. 
Depending on recovery times relative to event frequency, repeat events may mean that ultimately populations are unable to recover fully from each subsequent collapse, thereby leading to local extinction. However, interactions with landscape characteristics provide potential opportunities for climate change adaptation. Habitat restorations may reduce the degree of population collapse in response to extreme events and additionally aid recovery ${ }^{10}$. Although evidence of the existence of these land use-climate interactions is emerging ${ }^{3 ; 10 ; 11}$, there has been no quantitative assessment of their effectiveness under future climate change. Such evidence is critical to aid decision making in the context of safeguarding climatesensitive species.

Here we use extensive long-term butterfly population data from 129 sites of the UK Butterfly Monitoring Scheme (UKBMS) to assess historical responses of 28 species to an extreme drought event in $1995^{12 ; 13}$. This was the most arid summer since records began in 1776, measured using an April-September aridity index ${ }^{13}$. Although butterflies are generally regarded as warmth-loving species, extreme hot and dry periods, can drastically reduce population sizes through direct heat stress to larvae, or through declines in host-plant quality and quantity arising from soil moisture deficits ${ }^{14-17}$. The UKBMS data in combination with satellite-derived land cover data ${ }^{18}$ allow characterisation of how area and configuration of Semi-Natural Habitat (SNH) in surrounding landscapes modify species responses to drought. We identify six drought sensitive butterfly species (Fig. 1) as those that had negative relationships between interannual growth rate and annual aridity and which exhibited major population collapses following the 1995 drought (see Supplementary Methods \& Supplementary Fig. 1). For these populations, we assess recovery rate as the slope of population change in the subsequent four years. We use multispecies mixed effects models fitted to all species data ${ }^{19}$, with control variables which account for spatial variation in drought intensity, density dependent population growth rates, and non-independence of data 
within sites and species. We find that both response parameters, characterising size of population collapse and recovery rate, are associated with habitat area and fragmentation in $3 \mathrm{~km}$ radii around monitoring site. Of particular note is that larger extents of SNH in landscapes are associated with lower population collapses in response to drought, whilst reduced habitat fragmentation (lower 'edginess' of SNH) is associated with faster butterfly recovery (Table 1, Supplementary Fig.2). Larger areas of contiguous habitat contain a greater amount and diversity of host and nectar resources and microclimatic conditions ${ }^{11 ; 20}$ and are also less impacted by edge effects (i.e. moisture deficits towards woodland edges) during drought periods ${ }^{21 ; 22}$. Additionally, reduced habitat fragmentation may also allow 'rescue effects' through improved connectivity from nearby populations ${ }^{23}$.

Extremes of very hot and dry periods are projected by many climate models to increase in response to raised levels of atmospheric greenhouse gas concentrations ${ }^{1-3}$. To assess such future drought likelihoods, the CMIP5 database ${ }^{24}$ provides a comprehensive repository of climate projections with a broad set of contemporary Global Climate Models (GCMs) and for four RCP scenarios ${ }^{25}$. The largest increases in atmospheric greenhouse gases are for RCP8.5, corresponding to a radiative forcing of approximately $8.5 \mathrm{Wm}^{-2}$ for year 2100. Sometimes referred to as a "business-as-usual" scenario, this corresponds to major ongoing emissions throughout the $21^{\text {st }}$ Century, with little abatement ${ }^{26}$. The smallest change is with RCP2.6, (stabilisation at 2.6 $\mathrm{Wm}^{-2}$ ), which for many climate models is associated with an eventual warming since pre-industrial times of approximately two degrees Celsius. We extract monthly temperature and precipitation data for the complete set of available GCM simulations for a point representative of central England and corresponding to 100\% land cover for each GCM. These data are used to calculate a 6-month summer aridity index (hereafter aridity) $^{13}$ for each model year from 1860-2100, which captures the combined 
impacts of high temperatures and rainfall deficit as a single indicator of drought intensity (Fig. 2a).

Under CMIP5 projections, aridity increases in all GCMs, but the amount of change varies between different models. As expected, it also differs between RCPs, with the largest increases being for RCP8.5 (Fig. 2a \& Supplementary Fig. 3), although all estimate that higher frequencies of “1995-like” drought events will occur during the $21^{\text {st }}$ Century. Historically, the return time of aridity events as intense as in 1995 has been greater than 238 years based on record length. Yet by year 2100 projected return time is every $6.15 \pm 1.21$ (SE) years under the RCP2.6 pathway, and every $1.29 \pm 0.31$ years under RCP8.5 (i.e. effectively every year, Supplementary Figs. 3 \& 4).

In order to explore impacts of possible land use change, we project population changes in response to mean, and high and low (latter two defined as mean \pm s.d., respectively; Fig. 2b) values for both $\mathrm{SNH}$ area and edge index in 3km radii around butterfly monitoring scheme sites, to evaluate the adaptive potential of these five landscapes (labelled as SNH scenarios A-E in Fig. 2b \& c).

We next calculate the probability that drought-sensitive butterfly populations can persist in relation to co-variation in climate and habitat, under these different atmospheric RCP and land use scenarios. We use 30-year running means of annual aridity to place particular attention on whether recovery times exceed return times of drought as projected climate change unfolds, a situation that would lead to continual population erosion and ultimately local extinction. This conservative approach assumes that drought events are regularly spaced, whereas in reality they may be clustered, potentially further hampering recovery. Breaking this assumption would produce more severe projections of butterfly persistence, but would unjustifiably rely on the exact timing of extreme events in any particular GCM simulations. Additionally, in the absence of historical analogues, we make 
the conservative assumption that all future droughts will have the same impact as the 1995 event, even though they may be more severe in terms of aridity (Supplementary Fig. 3); whilst there may also be negative impacts of drought events of lower magnitude than 1995 (Supplementary Fig. 1). We incorporate uncertainty between climate models by considering under what proportion of GCMs, in each RCP, butterfly populations would be likely to persist (i.e. where recovery time is less than drought return time), thereby providing a probabilistic estimate. Uncertainty in butterfly recovery times is captured by using our confidence intervals on the multispecies model parameters to calculate upper and lower recovery times for each landscape.

Our forward projections show that the probability of butterfly population persistence varies strongly with both atmospheric forcing levels and land use scenario (Fig. 3). We find that no level of landscape management explored would allow successful climate change adaptation and persistence under RCP8.5: widespread local population extinctions will occur by 2100, and as early as 2050 for highly fragmented landscapes (Fig. 3c \& d) including the current average situation around monitoring sites (Fig. 3e). The most favourable of the considered landscapes has the highest SNH area and lowest fragmentation and under RCP2.6 achieves a 50\% probability of population persistence (95 percent confidence range: 29-64\%) by 2050 (Fig. 3a). Higher population persistence is predicted under the low fragmentation but low SNH total area scenario (Fig. 3b) than the average fragmentation and SNH total area scenario (Fig. 3e). Therefore, contrary to recent current thinking ${ }^{27}$, this shows that it is more important that habitat creation is targeted to reduce fragmentation than solely to maximise area. Further SNH fragmentation (e.g. under landscape management aimed to satisfy food and energy security) would result in very low probabilities of butterfly persistence (i.e. under 30\% by 2050) under all mitigation strategies (Fig. 3c \& d). 
Across the long-running butterfly monitoring sites studied, landscapes in 3km radius tend to have slightly higher total SNH area than the national average, but this SNH tends to be more fragmented (Fig. 2b). This reflects these monitoring sites being generally located in large SNH patches but also placed in intensive agricultural landscapes of Southern Britain (Supplementary Fig. 5). Therefore the average national landscape is most likely nearer that of SNH scenario B, for which Fig. 3b indicates will harbour populations that are slightly more robust in the face of climate change. However, even accounting for this, to ensure future persistence in such landscapes still requires emissions trajectories falling strongly away from “business-as-usual”. Under SNH scenario B, and RCP2.6, persistence probabilities are between 14-50\% (95\% CI) by in the latter half of the century, with other scenarios significantly lower (Fig. 3b).

Our empirical models and subsequent projections demonstrate the significant interacting impacts of land use and extreme drought on butterfly populations. It is possible that microevolution of drought tolerance could mitigate some future impacts. Whilst there are examples where evolution in response to climate change can occur rapidly ${ }^{28}$, there are also a number of recognised mechanisms why it may often not occur ${ }^{11 ; 29}$. This is especially the case when populations are smaller, as are British populations in light of historical declines ${ }^{30}$. There are also upper limits on physiological tolerance to drought, as evidenced by the absence of butterflies from high aridity locations in Europe ${ }^{17}$. Therefore, we believe that microevolutionary rescue over the next four decades is unlikely, and that landscape management offers the best solution to preventing extinctions.

Our analysis is the first to consider alternative outcomes of coincident changes in the frequency of extreme events and land use. The focus has been on drought-sensitive butterflies, and for Southern Britain, although our methods are applicable elsewhere and with monitoring data for other species. As time evolves, more severe drought events will occur, 
and on-going maintenance of species monitoring datasets will allow analysis of such extreme events, including impacts on species not currently identified as drought-sensitive. From these, we will be able to assess the extent to which our derived model parameters defining butterfly population responses may experience any modulation through other stochastic environmental factors, such as interactions with other species. From the current study, however, we provide strong evidence of the potential for climate change adaptation measures, in particular the unexpected importance of reducing SNH fragmentation, to delay responses to increased drought frequency under climate change. A targeted approach to using land efficiently offers the potential to maximise conservation benefits with the minimum impact on other land uses such as food and energy production. However, to ensure persistence of drought sensitive species through the entire $21^{\text {st }}$ Century, then a combination of major emissions reductions, for instance in line with scenario RCP2.6, along with significant reductions in habitat fragmentation are required. 


\section{References}

1 Seneviratne, S.I., Donat, M.G., Mueller, B., and Alexander, L.V., No pause in the increase of hot temperature extremes. Nature Clim. Change 4, 161 (2014). Cai, W. et al., Increasing frequency of extreme El Nino events due to greenhouse warming. Nature Clim. Change 4, 111 (2014).

Settele, J. et al., Terrestrial and inland water systems. in Climate Change 2014: Impacts, Adaptation, and Vulnerability. Part A: Global and Sectoral Aspects. Contribution of Working Group II to the Fifth Assessment Report of the Intergovernmental Panel on Climate Change edited by C.B. Field et al. (Cambridge University Press, Cambridge, United Kingdom and New York, NY, USA, 2014), pp. 271. Jentsch, A., Kreyling, J., and Beierkuhnlein, C., A new generation of climate-change experiments: events, not trends. Front. Ecol. Env. 5, 365 (2007). Bellard, C. et al., Impacts of climate change on future biodiversity. Ecol. Lett. 15, 365 (2012).

Thuiller, W. et al., Consequences of climate change on the tree of life in Europe. Nature 470 (2011). Jiguet, F., Brotons, L., and Devictor, V., Community responses to extreme climatic conditions. Curr. Zool. 57, 406 (2011). Jiguet, F. et al., Thermal range predicts bird population resilience to extreme high temperatures. Ecol. Lett. 9, 1321 (2006). Easterling, D.R. et al., Climate Extremes: Observations, Modeling, and Impacts. Science 289, 2068 (2000). 
Oliver, T.H. and Morecroft, M.D., Interactions between climate change and land use change on biodiversity: attribution problems, risks, and opportunities. Wiley Interdisciplinary Reviews: Climate Change 5, 317 (2014). Hof, C., Levinsky, I., Araújo, M.B., and Rahbek, C., Rethinking species' ability to cope with rapid climate change. Glob. Ch. Biol. 17, 2987 (2011). Morecroft, M.D. et al., Effects of drought on contrasting insect and plant species in the UK in the mid-1990s. Glob. Ecol. Biogeogr. 11, 7 (2002). Marsh, T., Cole, G., and Wilby, R., Major droughts in England and Wales, 18002006. Weather 62, 87 (2007). Talloen, W., Dyck, H.V., and Lens, L., The cost of melanisation: butterfly wing colouration under environmental stress. Evolution 58, 360 (2004). WallisDeVries, M.F., Baxter, W., and Van Vliet, A.J.H., Beyond climate envelopes: effects of weather on regional population trends in butterflies. Oecologia 167, 559 (2011).

Gutbrodt, B., Mody, K., and Dorn, S., Drought changes plant chemistry and causes contrasting responses in lepidopteran herbivores. Oikos 120, 1732 (2011). Settele, J. et al., Climatic Risk Atlas of European Butterflies. (Pensoft Publishers, Sofia, 2008).

Fuller, R.M., Smith, G.M., Hill, R.A., and Thomson, A.G., The UK Land Cover Map 2000: Construction of a parcel-based vector map from satellite images. Cartographic Journal 39, 15 (2002). Bolker, B.M. et al., Generalized linear mixed models: a practical guide for ecology and evolution. Trends Ecol. Evol. 24, 127 (2008). 13, 473 (2010). 
Herbst, M. et al., Edge effects and forest water use: A field study in a mixed deciduous woodland. For. Ecol. Man. 250, 176 (2007). Morecroft, M.D., Taylor, M.E., and Oliver, H.R., Air and soil microclimates of deciduous woodland compared to an open site. Agr. For. Meteor. 90, 141 (1998). Hanski, I., Metapopulation Ecology. (Oxford University Press, Oxford, 1999). Taylor, K.E., Stouffer, R.J., and Meehl, G.A., An Overview of CMIP5 and the Experiment Design. Bull. Am. Meteorol. Soc. 93, 485 (2011). van Vuuren, D. et al., The representative concentration pathways: an overview. Clim. Change 109, 5 (2011). Sanford, T., Frumhoff, P.C., Luers, A., and Gulledge, J., The climate policy narrative for a dangerously warming world. Nature Clim. Change 4, 164 (2014). Hodgson, J.A., Moilanen, A., Wintle, B.A., and Thomas, C.D., Habitat area, quality and connectivity: striking the balance for efficient conservation. J. Appl. Ecol. 48, 148 (2011). van Asch, M. et al., Evolutionary response of the egg hatching date of a herbivorous insect under climate change. Nature Clim. Change 3, 244 (2013). Etterson, J.R. and Shaw, R.G., Constraint to adaptive evolution in response to global warming. Science 294, 151 (2001). Fox, J.A. et al., The State of the UK's Butterflies 2011. (Butterfly Conservation and the Centre for Ecology and Hydrology, Wareham, Dorset, 2011). 


\section{Methods}

\section{Climate and habitat data}

The aridity index was calculated as the weighted sum of the standardised April-October temperature average and precipitation totals as in Marsh et $a{ }^{31}{ }^{31}$. Observed aridity index was derived from the updated Central England Temperature ${ }^{32}$ and England and Wales Rainfall ${ }^{33}$ monthly series, obtained from the UK Met Office. Projected aridity indices were derived from 2-m air temperature and total precipitation monthly fields, obtained from the CMIP5 project (Extended Data Table 1). All aridity index series use the same reference period (18602005) for standardisation. To avoid bias due to the unequal number of ensemble members associated with each GCM, each GCM aridity index was calculated from the ensemble mean standardised temperature and precipitation time series for that GCM.

Semi-natural habitat was assessed as all land cover types besides urban, suburban, arable, improved grassland and saltwater from LCM $2000^{34}$, a UK national land cover map derived from satellite earth observation, in 3km radii around UKBMS monitoring sites. Preliminary analyses and previous work suggest that landscape structure at this spatial scale has strong impacts on butterfly population dynamics ${ }^{35 ; 36}$. Configuration metrics were calculated using the program FRAGSTATS ${ }^{37}$. Three metrics were selected which reflect complementary aspects of fragmentation and potentially mediate butterfly responses to drought ${ }^{36}$ : mean 'edge index' (a standardised measure of area-perimeter ratio or 'edginess', where for each separate SNH patch the actual perimeter is expressed relative to the minimum possible perimeter for a patch of that size and the mean taken across all patches), mean nearest neighbour distance between habitat patches and patch density (number of patches per $\mathrm{m}^{2}$ ).

\section{Attribution of drought impacts on butterfly species}


We used data from the UK butterfly monitoring scheme (http://www.ukbms.org/) for which annual indices of abundance at each monitoring site have been calculated ${ }^{38}$. Species needed to fulfil three criteria in order to be categorised as especially drought-sensitive. First, a significant majority of monitoring sites should show population declines following the drought relative to expected values in 1996 from a six-year local population trajectory (e.g. Fig. 1a \& b; assessed using a Wilcoxon signed ranks test). Second, a significant majority of monitoring sites should also show significant population declines relative to the year immediately preceding the drought. Finally, across all years that sites were monitored the species should show a significant negative relationship between interannual growth rates and annual summer aridity index. Interannual growth rates were calculated as $\log (\mathrm{Nt} / \mathrm{Nt}-1)$, where $\mathrm{N}$ is the population density in year $\mathrm{t}$. This was then used as a response variable in a linear mixed effects regression against annual aridity index in year $\mathrm{t}$ with Site as a random effect in order to account for multiple observations at each monitoring site. These three tests resulted in just over one-fifth of UK species identified as drought sensitive under our criteria (Extended Data Fig. 1).

We analysed the effect of semi-natural habitat (SNH) on degree of population collapse from the 1995 drought event and subsequent recovery ${ }^{31}$, following methods used by Oliver et al. ${ }^{36}$ and explained here. For each species at each monitoring site, the degree of population change in response to the 1995 drought was measured by the difference between the observed and expected population count in 1996 (from a six-year linear population trend; Fig. 1a). This method accounts for long term population trajectory, which is important because long term species declines ${ }^{39}$ could lead to false attribution of drought impacts if only change from the preceding years count is considered. A six-year period was chosen to assess the population trajectory because preliminary analysis suggested that this time period maximised statistical power by balancing accurate assessment of pre-drought population 
trends with higher sample size for sites included in the analysis ${ }^{36}$. Also in preliminary analyses, we tested for effects of density dependence on interannual growth rates (regression of $\log (\mathrm{Nt} / \mathrm{Nt}-1)$ versus $\mathrm{Nt}-1$, where $\mathrm{N}$ is population density in year $\mathrm{t})^{40}$. We found $43 \%$ of the population time series showed evidence of density dependence (at $\mathrm{p}<0.05$ ). However, in an analysis comparing linear and quadratic models to explain population trends over the six year period (i.e. regression of Nt on year), we found that linear models produced the best fit to population trends (for 92\% of time series). Therefore, although density dependence may be an important regulatory demographic process for these butterfly species, over the time periods and range of densities on our sites, and relative to other factors (e.g. weather and habitat quality), there is little evidence of curvature in population trends expected under a strong influence of density dependence. For all species and sites with population declines following the drought, recovery was assessed as the linear population trend in the subsequent four years (Fig. 1a), chosen to balance assessment of the population growth phase immediately following population collapse balanced with obtaining a reliable trend estimate $^{36}$. In models predicting recovery rates, extent of population collapse and starting population size following collapse were also included as covariates to account for density dependence in growth rates.

\section{Butterfly drought responses in relation to habitat fragmentation}

To data from all monitoring sites, and for all six drought-sensitive butterfly species, we fitted one linear mixed-effects model (LMM) investigating the predictors of population collapse from drought (difference between observed and expected count) and one LMM investigating the predictors of population recovery (rate of population increase following decline in 1995 or 1996). The model exploring the predictors of population collapse included expected population size and a measure of each site’s drought intensity (1995 aridity index from 
nearest $5 \mathrm{~km}$ cell) as control explanatory variables. All models exploring the predictors of recovery rates included the size of the initial population decline and population size immediately after the drought as control explanatory variables. In addition to these control variables, each of these models included four fixed effects characterising SNH: total SNH area and the three FRAGSTATS metrics described above. Each model also included site and species as random intercepts to control for repeated measures from the same site and the same species. All habitat variables were standardised to have a mean of zero and standard deviation of one (i.e. by subtracting the mean and dividing by standard deviation). Model checking confirmed the residuals from each mixed model containing all variables were normally distributed and had constant variance. To find the minimum adequate model the least significant habitat variable was sequentially dropped until no more could be dropped without losing a significant amount of explanatory power, determined by using a $\chi^{2}$ test to compare the model residual variances ${ }^{41}$. This resulted in only SNH area and edge index in the final models for population collapse and recovery respectively (see main text). Analyses were conducted using the program $\mathrm{R}$ and lme4 package $\mathrm{e}^{42 ; 43}$.

\section{Estimating butterfly recovery times}

We used the coefficients from the minimum adequate models for butterfly population collapse and recovery to calculate the average expected butterfly recovery time under the five different SNH scenarios (Fig. 2b \& c). Recovery time was calculated as the degree of population collapse to drought (expected minus observed population count following the drought event) divided by the post-drought population recovery rate (change in population count per year). To parameterise the models we used the mean expected population size, observed population size and site aridity index across all species and sites, along with either 'high’ (mean + s.d. across all sites), 'low’ (mean - s.d. across all sites) or mean values for 
SNH area and edge index. These produced predicted population recovery times under five SNH scenarios, e.g. high area and high edge index (main text and Fig. 2). We incorporated uncertainty by repeating these calculations using 95\% confidence intervals for coefficients to calculate the upper of lower uncertainty bounds on recovery times. Recovery times were then considered in relation to the time-varying drought return time under the four different RCPs. Uncertainty across GCMs was accounted for by expressing the percentage of climate projections in which populations would persist (where average recovery times were less than drought return times).

\section{References for Methods} 2006. Weather 62, 87 (2007). Meteorol. Soc. 100, 389 (1974).

Alexander, L.V. and Jones, P.D., Updated Precipitation Series for the U.K. and Discussion of Recent Extremes. Atmospheric Science Letters 1, 142 (2001). Fuller, R.M., Smith, G.M., Hill, R.A., and Thomson, A.G., The UK Land Cover Map 2000: Construction of a parcel-based vector map from satellite images. Cartographic Journal 39, 15 (2002). 13, 473 (2010). Oliver, T.H., Brereton, T., and Roy, D.B., Population resilience to an extreme drought is influenced by habitat area and fragmentation in the local landscape. Ecography 36, 579 (2013). 

Pattern Analysis Program for Categorical Maps. Computer software program produced by the authors at the University of Massachusetts, Amherst. Available at the following web site: www.umass.edu/landeco/research/fragstats/fragstats.html. (2002).

Rothery, P. and Roy, D.B., Application of generalized additive models to butterfly transect count data. J. Appl. Stat. 28, 897 (2001). Fox, J.A. et al., The State of the UK's Butterflies 2011. (Butterfly Conservation and the Centre for Ecology and Hydrology, Wareham, Dorset, 2011). Schtickzelle, N. and Baguette, M., Metapopulation viability analysis of the bog fritillary butterfly using RAMAS/GIS. Oikos 104, 277 (2004). Crawley, M.J., The R Book. Second Edition. (John Wiley and Sons, Chichester, UK, 2012).

R Core Team, $R$ : A language and environment for statistical computing. $R$ Foundation for Statistical Computing, Vienna, Austria. (http://www.R-project.org/, 2013).

Bates, D., Maechler, M., Bolker, B., and Walker, S., Ime4: Linear mixed-effects models using Eigen and S4. R package version 1.0-4. (http://CRAN.Rproject.org/package=lme4, 2013). 
Acknowledgements: This research was partly funded by Natural England Project ref. 24802 and partly by NERC CEH national capability funding. We thank Andrew Crowe from the UK Food and Environment Research Agency for calculating habitat configuration metrics and Simon Duffield for help in establishing the project. The UKBMS is funded by funded by a multi-agency consortium led by Defra, and including CCW, JNCC, FC, NE, NERC, NIEA, SNH.

Author Contributions: THO conceived the study with input from MM; CP and CH analysed climate data; HHM and THO analysed butterfly responses to habitat and climate; all authors interpreted results and contributed to writing the manuscript.

Author information: Correspondence and requests for materials should be addressed to toliver@ceh.ac.uk. The authors confirm they have no competing financial interests. 


\section{Figure Legends}

Figure 1, The impacts of historical drought on sensitive butterfly species. Panel a shows an example response of a single population of Pararge aegeria showing degree of population collapse (vertical dotted line) and recovery rate (solid line) from the 1995 drought event. Panel b demonstrates identification of this species as ‘drought-sensitive’ from its decline across a significant proportion of sites (see Figure S1 for additional criteria). Panel c gives the median population collapse and recovery rate for each of the species shown in panel d, with interquartile range for both in parentheses.

Figure 2, Scenarios of land use change and aridity in a future climate. Panel (a) shows projected changes in annual aridity index for central England under different RCP emissions scenarios from 17 CMIP5 global circulation models. Observed data from the UK Met Office are shown as black points with a 5 year moving average trend line. Aridity in 1995 is shown by the dashed horizontal line. Panel (b) shows semi-natural habitat (SNH) metrics in 3km radii around the 129 butterfly monitoring scheme sites analysed (open black circles and contours showing probability density surface, with vertical and horizontal lines showing \pm SD from the mean). The lettered intersections (“A”-“D”) refer to the habitat scenarios for which we modelled butterfly persistence under future climate projections, along with the current mean habitat (“E”). Also in panel (b), the black points and coloured probability density surface show the ‘average’ English landscape from SNH metrics in 3km radii around 2443 stratified randomised samples across lowland England. Panel (c) shows four butterfly monitoring sites which exemplify the SNH characteristics one standard deviation away from the monitoring site means corresponding to the labelled intersections " $A$ ”-“ $D$ ” in panel (b). 
Figure 3, Combined effects of climate change and habitat. The percentage of GCMs for which butterfly persistence occurs; that is where return time of severe drought events is longer than the recovery time of the average butterfly population in a 30-year moving window, under four semi-natural habitat scenarios, with lettering matching scenarios in Fig. 2: panel (a)- high area and low edge index; (b)- low area and edge index; (c)-high area and edge index; (d)- low area and high edge index; (e)- current mean around monitoring sites. Lines within each plot show the predictions under two RCP extreme emissions pathways (RCP26 in blue, RCP85 in red, with 95\% confidence intervals as shaded envelopes). Results from intermediate RCP pathways RCP4.5 (orange) and RCP6.0 (black) are also incorporated on the right hand side bars which show the probability of persistence with maximum $\pm 95 \%$ CI between 2050 and 2100 (i.e. between 30-year window midpoints 2065-2085). 


\section{Tables}

Table 1, Variable coefficients from minimum adequate mixed effects models relating butterfly population collapse and recovery from drought to SNH habitat characteristics.

Models include all six drought species identified as particularly drought-sensitive (see main text). Control variables were also included in the models (see Supplementary Methods for details). T-values in bold indicate significant effects (at $\mathrm{p}<0.05$ ).

\begin{tabular}{|c|c|c|c|c|c|}
\hline Model & Response variable & Explanatory variable & Coefficient & SE & $\mathbf{t}$ \\
\hline 1 & Population collapse & Intercept & -0.36 & 13.70 & -0.03 \\
\hline \multirow[t]{2}{*}{1} & Population collapse & Expected abundance from long & & & \\
\hline & & term trajectory (control) & 0.40 & 0.02 & 20.39 \\
\hline 1 & Population collapse & Site aridity (control) & 0.57 & 3.00 & 0.19 \\
\hline 1 & Population collapse & SNH area & -10.44 & 3.45 & -3.02 \\
\hline 2 & Recovery rate & Intercept & 7.08 & 5.98 & 1.18 \\
\hline \multirow[t]{2}{*}{2} & Recovery rate & Population collapse from & & & \\
\hline & & drought (control) & 0.03 & 0.02 & 1.79 \\
\hline \multirow[t]{2}{*}{2} & Recovery rate & Starting population size after & & & \\
\hline & & collapse (control) & -0.05 & 0.02 & -3.00 \\
\hline 2 & Recovery rate & SNH edge index & -3.65 & 1.55 & -2.36 \\
\hline
\end{tabular}

